\title{
A complex regulatory network controls aerobic ethanol oxidation in Pseudomonas aeruginosa: indication of four levels of sensor kinases and response regulators
}

\author{
Demissew S. Mern, ${ }^{1}$ Seung-Wook Ha, ${ }^{2}$ Viola Khodaverdi, ${ }^{3}$ Nicole Gliese ${ }^{4}$ \\ and Helmut Görisch ${ }^{3}$ \\ ${ }^{1}$ Helmholtz-University Group Molecular Epidemiology, German Cancer Research Center, Im \\ Neuenheimer Feld 581, D-69120 Heidelberg, Germany \\ ${ }^{2}$ The Barbara Ann Karmanos Cancer Institute, Wayne State University School of Medicine, Detroit, \\ Ml 48201, USA \\ ${ }^{3}$ Fachgebiet Angewandte Biochemie, Institut für Biotechnologie, Technische Universität Berlin, \\ Seestrasse 13, D-13353 Berlin, Germany \\ ${ }^{4}$ BioGenes GmbH, Koepenicker Strasse 325, D-12555 Berlin, Germany
}

Correspondence

Helmut Görisch

helmut.goerisch@tu-berlin.de

In addition to the known response regulator ErbR (former AgmR) and the two-component regulatory system EraSR (former ExaDE), three additional regulatory proteins have been identified as being involved in controlling transcription of the aerobic ethanol oxidation system in Pseudomonas aeruginosa. Two putative sensor kinases, ErcS and ErcS', and a response regulator, ErdR, were found, all of which show significant similarity to the two-component flhSR system that controls methanol and formaldehyde metabolism in Paracoccus denitrificans. All three identified response regulators, EraR (formerly ExaE), ErbR (formerly AgmR) and ErdR, are members of the luxR family. The three sensor kinases EraS (formerly ExaD), ErcS and ErcS ${ }^{\prime}$ do not contain a membrane domain. Apparently, they are localized in the cytoplasm and recognize cytoplasmic signals. Inactivation of gene ercS caused an extended lag phase on ethanol. Inactivation of both genes, ercS and erc $S^{\prime}$, resulted in no growth at all on ethanol, as did inactivation of erdR. Of the three sensor kinases and three response regulators identified thus far, only the EraSR (formerly ExaDE) system forms a corresponding kinase/regulator pair. Using reporter gene constructs of all identified regulatory genes in different mutants allowed the hierarchy of a hypothetical complex regulatory network to be established. Probably, two additional sensor kinases and two additional response regulators, which are hidden among the numerous regulatory genes annotated in the genome of $P$. aeruginosa, remain to be identified.

Received 17 July 2009

Revised 15 January 2010

Accepted 18 January 2010

\section{INTRODUCTION}

The Gram-negative bacterium Pseudomonas aeruginosa ATCC 17933 is able to grow aerobically on ethanol as the sole source of carbon and energy. The initial step, converting ethanol to acetaldehyde, is catalysed by a periplasmic quinoprotein ethanol dehydrogenase (QEDH), with 2,7,9tricarboxypyrroloquinoline quinone (PQQ) as prosthetic group (Rupp \& Görisch, 1988). QEDH is linked to an electron transport chain that includes soluble cytochrome $c_{550}$ and a co-type cytochrome oxidase (Reichmann \& Görisch, 1993; Matsushita et al., 1982). The PQQ cofactor can be removed reversibly, and incubation of the apoform

Abbreviations: MU, Miller units; $\mathrm{PQQ}$, pyrroloquinoline quinone; $\mathrm{OEDH}$, quinoprotein ethanol dehydrogenase. with PQQ and $\mathrm{Ca}^{2+}$ leads to a fully active enzyme (Mutzel \& Görisch, 1992). The X-ray structure has been solved at $2.6 \AA$ resolution and reveals that the backbone folding and the active site of QEDH are very similar to those of the large subunits of the PQQ-dependent quinoprotein methanol dehydrogenases (QMDHs) of Methylobacterium extorquens and Methylophilus W3A1 (Keitel et al., 2000; Ghosh et al., 1995; Xia et al. 1996). Recently, we demonstrated that the unusual disulfide ring formed by adjacent cysteine residues present in QEDH is essential for efficient electron transfer to cytochrome $c_{550}$ (Mennenga et al., 2009).

Studies with a number of regulatory mutants have revealed that ethanol oxidation in $P$. aeruginosa is controlled by at least seven genes organized in a complex network, where the different components act in a hierarchical manner 
(Görisch, 2003). Three of these genes have been identified so far: a two-component regulatory system, EraSR (formerly ExaDE), which encodes a sensor kinase and the respective response regulator, controlling transcription of the exaA gene, encoding QEDH (Schobert \& Görisch, 2001). The response regulator ErbR (formerly AgmR) controls transcription of the eraSR (formerly exaDE) twocomponent system, the exaBC operon encoding cytochrome $c_{550}$ and an aldehyde dehydrogenase, as well as the pqq operon encoding the enzymes needed for PQQ biosynthesis (Gliese et al., 2004). As shown in Fig. 1, the operons of the exa and $p q q$ genes are clustered together on the genome of P. aeruginosa PAO1 (Stover et al., 2000).

Here we report the identification of two additional sensor kinases, ErcS and ErcS', encoded by genes PA1992 and PA1976, and a response regulator, ErdR, encoded by gene PA3604, all of which are involved in the regulation of the ethanol oxidation system in $P$. aeruginosa. The three genes show significant similarity to the Paracoccus denitrificans flhSR two-component system, which controls methanol and formaldehyde metabolism in that organism (Harms et al., 2001). Genes PA1976 and PA1992 were studied because they are located in close proximity to the era and pqq gene clusters (Fig. 1). Gene PA3604 was identified by searching the genome of $P$. aeruginosa for further response regulators with significant similarity to the Paracoccus denitrificans flhSR system. The regulatory genes discussed in the present study are listed in Table 1 with their current names and annotation together with their new suggested names.

\section{METHODS}

Bacterial strains and culture conditions. The strains and plasmids used in this study are listed in Table 2. Escherichia coli strains were cultivated at $37^{\circ} \mathrm{C}$ in Luria-Bertani (LB) medium; P. aeruginosa ATCC 17933 and mutants were cultivated in LB or minimal medium supplemented with different carbon sources (Rupp \& Görisch, 1988). Glucose $(40 \mathrm{mM})$, succinate $(40 \mathrm{mM})$, acetate $(20 \mathrm{mM})$ and $0.5 \%$ $(\mathrm{v} / \mathrm{v})$ of alcohols were used. When appropriate, the following antibiotics were added to the media: $100 \mu \mathrm{g}$ carbenicillin $\mathrm{ml}^{-1}, 50 \mu \mathrm{g}$ kanamycin $\mathrm{ml}^{-1}, 50 \mu \mathrm{g}$ gentamicin $\mathrm{ml}^{-1}$ and $20 \mu \mathrm{g}$ tetracycline $\mathrm{ml}^{-1}$.

General genetic techniques. DNA manipulations were performed according to the protocols described by Sambrook et al. (1989) and
Ausubel et al. (2002). For PCRs, genomic DNA isolated from $P$. aeruginosa ATCC 17933 was used as template, and for primer design, the sequence of $P$. aeruginosa strain PAOl was used, as the nucleotide identity between PAO1 and ATCC 17933 is 99\% (Schobert, 1999; Stover et al., 2000). For amplification of gene PA3604, primers with restriction sites (indicated in bold, below) for $\mathrm{XbaI}$ and HindIII were used. The forward primer was 5'-AGCTCTAGAGCAGGCCGGTATAGAGGAAC-3' and the reverse primer was $5^{\prime}$-TCAGAAGCTTGACTGACGTCGAGGAGGAAG-3'. The $1.18 \mathrm{~kb}$ PCR product containing PA3604 was cloned into XbaI-HindIII sites of pUC18 and pUCP20T, resulting in plasmids pTB7076 and pTB7106. For amplification of gene PA1976, primers with restriction sites for HindIII were used. The forward primer was $5^{\prime}$-CAGGAAGCTTCACCGCGATGAGCACCGGT-3' and the reverse primer was $5^{\prime}$ CAGGAAGCTTCGGCTACGCCGTCTGGTAC-3'. The $3.07 \mathrm{~kb}$ PCR product containing PA1976 was cloned into the HindIII site of pUC19, resulting in plasmid pTB7029. For amplification of gene PA1992, primers with restriction sites for EcoRI and SphI were used. The forward primer was $5^{\prime}$-AGCGAATTCACCTGATCGCCTTCAAGCAC- $3^{\prime}$ and the reverse primer was 5'-ACTGAGCATGCTCCGCTCGATGTTCCTCTTC-3'. The 1.98 kb PCR product containing PA1992 was cloned into EcoRI-SphI sites of pUC18 and pUCP20T, resulting in plasmids pTB7100 and pTB7101. Electrotransformation of $P$. aeruginosa ATCC 17933 was performed as described by Smith \& Iglewski (1989). Triparental matings were performed as described previously (Kretzschmar et al., 2001).

Site-directed inactivation of genes. Site-directed inactivation of genes of $P$. aeruginosa ATCC 17933 by a kanamycin- or gentamicinresistance cassette was done by the $s a c B$-based strategy with the suicide vector pEX18Ap or pEX18Tc (Hoang et al., 1998). Sucroseresistant colonies were obtained by streaking $P$. aeruginosa merodiploids on LB plates supplemented with $5 \%$ sucrose. For inactivation of gene PA3604, the SmaI-digested kanamycin-resistance cassette was ligated into the blunted ApaI-PstI sites of pTB7076, resulting in pTB7077, and the insert was cloned into the XbaI-HindIII sites of pEX18Ap, resulting in pTB7078. The $\mathrm{Km}^{\mathrm{r}}$ gene is transcribed in the same orientation as the PA3604 gene. For inactivation of gene PA1976, the kanamycin-resistance cassette was ligated into the BsaI site of pTB7029, resulting in pTB7035, and the insert was cloned into the HindIII site of pEX18Tc, resulting in pTB7040. The same orientation of both genes was verified. For inactivation of gene PA1992, the gentamicin-resistance cassette was ligated into the BamHI site of pTB7100, resulting in pTB7103, and the insert was cloned into the EcoRI-XbaI sites of pEX18Ap, resulting in pTB7104. The $\mathrm{Gm}^{\mathrm{r}}$ gene is transcribed in the same orientation as the PA1992 gene. The suicide vectors were introduced into $P$. aeruginosa via triparental mating, and after two independent homologous recombinations, potential site-directed double-crossover mutants with a $\mathrm{Km}^{\mathrm{r}}$ $\left(\mathrm{Gm}^{\mathrm{r}}\right)-\mathrm{Cb}^{\mathrm{s}}-\mathrm{Suc}^{\mathrm{r}}$ phenotype were selected.

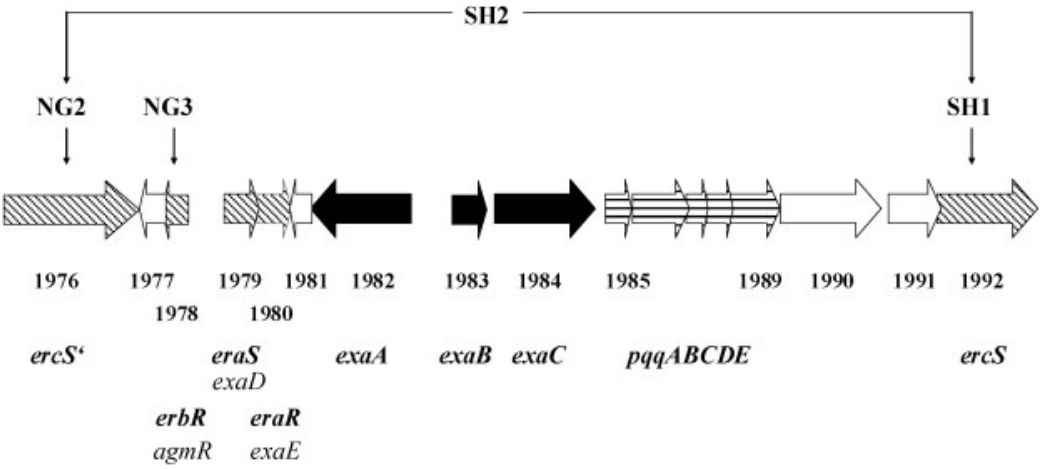

Fig. 1. Arrangement of the exa and era to erc genes on the chromosome of $P$. aeruginosa PAO1 and ATCC 17933. Genes exa, encoding components of ethanol oxidation metabolism, are shown in black; pqq genes are indicated by horizontal hatching. Regulatory genes eraSR (exaDE), erbR (agmR), ercS and erc $S^{\prime}$, controlling operons exa and $p q q$, are shown with diagonal hatching; gene erdR is not shown. Mutants discussed in the text are indicated by their names. 
Table 1. Renaming of the regulatory genes of the ethanol oxidation system in $P$. aeruginosa PAO1

$\mathrm{S}$, sensor kinase of two-component regulatory system; R, response regulator. exa, Ethanol oxidation genes cluster a, encode proteins needed for ethanol metabolism: exaA (QEDH), exaBC (cytochrome $c_{550}, \mathrm{NAD}^{+}$-dependent aldehyde dehydrogenase); era genes encode regulatory proteins controlling transcription of operon exaA: first level of two-component regulatory systems; erb genes encode regulatory proteins controlling transcription of operons eraSR, exaBC and pqqABCDE: second level of two-component regulatory systems; erc genes encode regulatory proteins controlling transcription of erb genes: third level of two-component regulatory systems; erd genes encode regulatory proteins controlling transcription of erc genes: fourth level of two-component regulatory systems.

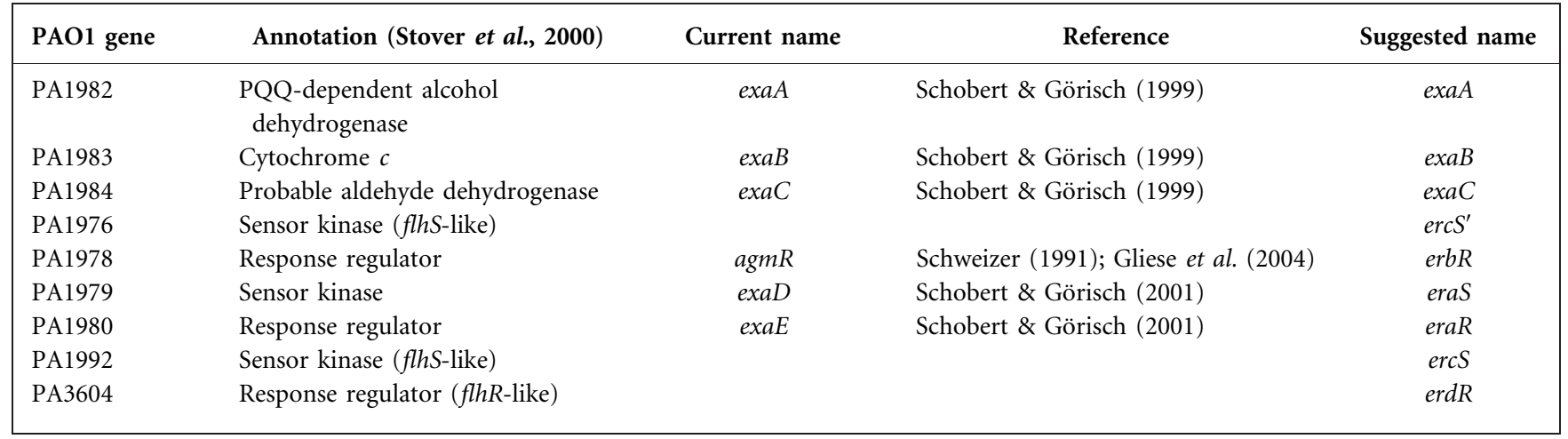

Promoter-probe vectors. Promoter-probe vectors were constructed to study the transcriptional regulation of genes PA3604 and erbR $(a g m R)$. A 280 bp promoter region of PA3604 was cloned into the XbaI-HindIII sites of pQF50 upstream of the lacZ gene (Farinha \& Kropinski, 1990), and a $1.0 \mathrm{~kb}$ promoter region of $\operatorname{agmR}$ was cloned into the KpnI-HindIII sites of pQF50, resulting in promoter-probe vectors pTB7107 and pTB7108, respectively. For amplification of the promoter region of PA3604, primers with restriction sites (indicated in bold, below) for $\mathrm{XbaI}$ and HindIII were used. The forward primer was 5'-AGCTCTAGATGATCAGCATCAGGACATCG-3' and the reverse primer was $5^{\prime}$-TCAGAAGCTTGGCGATCAGGATCTCGTAAG-3'. For amplification of the promoter region of erbR $(\operatorname{agmR})$, primers with restriction sites for KpnI-HindIII were used. The forward primer was 5'-CTAGGTACCAGCAGCCAGCGGTACTCC- $3^{\prime}$ and the reverse primer was $5^{\prime}$-TCTGAAGCTTCGTAGGTGATGGCCTGTAGC-3'.

To study transcription of the operon PA1991/PA1992, three different promoter-probe vectors were constructed. A $0.53 \mathrm{~kb}$ promoter region of PA1991, a $0.62 \mathrm{~kb}$ putative promoter region in front of PA1992, and a $1.7 \mathrm{~kb}$ region containing the promoter region of PA1991, gene PA1991 and the putative promoter of PA1992, were amplified by PCR and cloned into the XbaI-HindIII sites of pQF50 upstream of the lacZ gene, resulting in promoter-probe vectors pTB7082, pTB7083 and pTB7084, respectively. The primers used for these amplifications contained restriction sites for XbaI and HindIII. For amplification of the promoter region of PA1991, the forward primer was $5^{\prime}$ TAGTCTAGAGCCAGTCTCTATGGGGTCAG-3' and the reverse primer was $5^{\prime}$-TCAGAAGCTTGTAGTTGGCGACGCTGTG-3'. For amplification of the putative promoter region of PA1992, the forward primer was 5'-TAGTCTAGACTGATCGATGGCAATCTGG-3' and the reverse primer was $5^{\prime}$-TCAGAAGCTTACAGCCATTTGTAGCGGTTG-3'. The $1.7 \mathrm{~kb}$ fragment containing the promoter of PA1991, gene PA1991 and the putative promoter region of PA1992 was amplified using the forward primer 5'-TAGTCTAGAGCCAGTCTCTATGGGGTCAG- $3^{\prime}$ and the reverse primer 5' ${ }^{\prime}$-TCAGAAGCTTACAGCCATTTGTAGCGGTTG-3'.

Promoter-probe vectors of the genes exaA (pTB3138), exaBC (pTB3139), eraSR (exaDE) (pTB7074) and pqqABCDE (pTB7023) were as described previously (Schobert \& Görisch, 1999; Gliese et al., 2004). pTB3138, pTB3139 and pTB7023 are derivatives of pEDY305
(Schwartz et al., 1998); pTB7074 is a derivative of pQF50 (Farinha \& Kropinski, 1990).

$\boldsymbol{\beta}$-Galactosidase assay. $\beta$-Galactosidase activity was determined in toluene-treated cells according to the procedure of Miller (1992). Determination of $\beta$-galactosidase activity in mutants unable to grow on ethanol was performed after induction on ethanol, as described previously (Schobert \& Görisch, 2001).

Internet tools. The Pseudomonas Genome Database (http://www. pseudomonas.com; Winsor et al., 2009), was used to obtain DNA sequences of P. aeruginosa strain PAO1 (Stover et al., 2000). BLAST was used for DNA or protein database searches (Altschul et al., 1997).

\section{RESULTS AND DISCUSSION}

\section{Naming and renaming genes involved in ethanol oxidation and its regulation in $\boldsymbol{P}$. aeruginosa}

When naming the exa gene cluster we followed the suggestions given by Lidstrom et al. (1994). The three genes involved in ethanol oxidation form the linkage group a (Schobert \& Görisch, 1999). Later we found genes PA1979 and PA1980, separated from the linkage group exaABC by a gene encoding a small protein of unknown function, and which encode a two-component regulatory system. These genes control transcription of the exaA operon and were named exaDE (Schobert \& Görisch, 2001). In 2004 we identified AgmR as controlling transcription of the exaDE regulatory system and also transcription of operons exaBC and pqq (Gliese et al., 2004). AgmR, a response regulator encoded by PA1978, has been described as involved in glycerol metabolism (Schweizer, 1991). Inactivation of the $\operatorname{agmR}$ gene was later shown not to affect glycerol metabolism in $P$. aeruginosa PAO1 (Schweizer, 1992; Schweizer \& Po, 1996) and ATCC 17933 (Gliese et al., 2004). However, AgmR is an important 
Table 2. Strains and plasmids used in this study

In promoter-probe vectors, the putative promoter region and the truncated gene $X$ are indicated by $P_{-} X^{\prime}-l a c Z$.

\begin{tabular}{|c|c|c|}
\hline Strain or plasmid & Relevant genotype or phenotype & Source or reference \\
\hline \multicolumn{3}{|c|}{ P. aeruginosa strains } \\
\hline ATCC 17933 & Wild-type & Cetin et al. (1965) \\
\hline MD1 & ATCC 17933 derivative, PA3604:: Km ${ }^{\mathrm{r}}$ & This study \\
\hline MD2 & 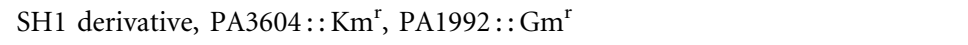 & This study \\
\hline NG2 & ATCC 17933 derivative, PA1976:: Km ${ }^{\mathrm{r}}$ & This study \\
\hline NG3 & ATCC 17933 derivative, agmR:: $\mathrm{Km}^{\mathrm{r}}$ & Gliese et al. (2004) \\
\hline SH1 & ATCC 17933 derivative, PA1992:: $\mathrm{Gm}^{\mathrm{r}}$ & This study \\
\hline $\mathrm{SH} 2$ & NG2 derivative, PA1992:: $\mathrm{Gm}^{\mathrm{r}}$, PA1976:: $\mathrm{Km}^{\mathrm{r}}$ & This study \\
\hline \multicolumn{3}{|l|}{ E. coli strains } \\
\hline $\mathrm{DH} 5 \alpha$ & supE44 $\Delta$ lacU169 ( $\phi 80 l a c Z \Delta \mathrm{M} 15)$ hsdR17 recA1 endA1 gyrA96 thi-1 relA1 & Hanahan $(1983)$ \\
\hline HB101 & supE44 hsdS20 $\left(r_{\mathrm{B}} m_{\mathrm{B}}\right)$ recA13 ara-14 proA2 lacYl galK2 rpsL20 xyl-5 mtl-1 & Boyer \& Roulland-Dussoix (1969) \\
\hline \multicolumn{3}{|c|}{ I } \\
\hline $\mathrm{pAC} \Omega \mathrm{Gm}$ & $\mathrm{Gm}^{\mathrm{r}}$; cloning vector with $\mathrm{Gm}^{\mathrm{r}}$ cassette and $\Omega$ fragments & Schweizer (1993) \\
\hline pEDY305 & $\mathrm{Tc}^{\mathrm{r}}$, lacZ promoter-probe vector & Schwartz et al. (1998) \\
\hline pEX18Ap & $\begin{array}{l}\mathrm{Ap}^{\mathrm{r}} \text {; oriT } \mathrm{T}^{+} \mathrm{sacB}^{+} \text {, gene replacement vector with multiple cloning site } \\
\text { (MCS) from pUC18 }\end{array}$ & Hoang et al. (1998) \\
\hline pEX18Tc & $\mathrm{Tc}^{\mathrm{r}} ;$ oriT $^{+} \mathrm{sacB}^{+}$, gene replacement vector with MCS from pUC18 & Hoang et al. (1998) \\
\hline pQF50 & $\mathrm{Ap}^{\mathrm{r}}$; lacZ promoter-probe vector & Farinha \& Kropinski (1990) \\
\hline pRK2013 & $\mathrm{Km}^{\mathrm{r}}$; helper plasmid for triparental mating & Figurski \& Helinski (1979) \\
\hline pUC18, pUC19 & $\mathrm{Ap}^{\mathrm{r}}$; cloning and expression vector & Yanisch-Perron et al. (1985) \\
\hline pUCP20T & $\mathrm{Ap}^{\mathrm{r}}$; broad-host-range vector & Schweizer et al. (1996) \\
\hline рTB3001 & $\begin{array}{l}\mathrm{Tc}^{\mathrm{r}} ; 25 \mathrm{~kb} \text { genomic DNA partially digested with Sau3AI from } P \text {. aeruginosa } \\
\text { cloned in BamHI site of pLAFR3 }\end{array}$ & Schobert \& Görisch (1999) \\
\hline рTB3070 & $\begin{array}{l}\mathrm{Ap}^{\mathrm{r}} ; 3.2 \mathrm{~kb} \text { BamHI-PstI fragment from pTB3001 cloned into BamHI-PstI } \\
\text { sites of pUC18 }\end{array}$ & Schobert \& Görisch (1999) \\
\hline pTB3131 & $\begin{array}{l}\mathrm{Ap}^{\mathrm{r}} \mathrm{Km}^{\mathrm{r}} ; 1.0 \mathrm{~kb} \text { PCR product with promoter and } \mathrm{Km}^{\mathrm{r}} \text { cassette of } \mathrm{Tn} 5 \\
\text { cloned into EcoRI-BamHI sites of pUC19 }\end{array}$ & Kretzschmar et al. (2001) \\
\hline pTB3138 & $\begin{array}{l}\mathrm{Tc}^{\mathrm{r}} ;\left(P \_ \text {exaA } A^{\prime} \text {-lacZ }\right) 0.89 \mathrm{~kb} \text { Pst } \mathrm{I}-\text { SalI fragment from pTB3070 cloned into } \\
\text { PstI-XhoI sites of pEDY305 }\end{array}$ & Schobert \& Görisch (2001) \\
\hline рTB3139 & $\begin{array}{l}\mathrm{Tc}^{\mathrm{r}} ;\left(P \_ \text {exaB'-lacZ) } 0.89 \mathrm{~kb} \text { Pst } \mathrm{I}-\mathrm{Xba \textrm {I }} \text { fragment from pTB3135 cloned into }\right. \\
\text { Pst } \mathrm{I}-\mathrm{X} b a \mathrm{I} \text { sites of pEDY305 }\end{array}$ & Schobert \& Görisch (2001) \\
\hline pTB7023 & $\begin{array}{l}\mathrm{Tc}^{\mathrm{r}} ;\left(P \_p q q A B^{\prime} \text { lacZ) } 2.5 \mathrm{~kb} \text { XhoI-BamHI fragment from pTB3070 cloned }\right. \\
\text { into XhoI-BglII sites of pEDY305 }\end{array}$ & Gliese et al. (2004) \\
\hline pTB7029 & $\mathrm{Ap}^{\mathrm{r}} ; 3.07 \mathrm{~kb}$ PCR product of gene PA1976 cloned into HindIII site of pUC19 & This study \\
\hline pТВ7035 & $\mathrm{Ap}^{\mathrm{r}} \mathrm{Km}^{\mathrm{r}} ; 4.07 \mathrm{~kb} \mathrm{Km}^{\mathrm{r}}$ cassette cloned into BsaI site of PA1976 in pTB7029 & This study \\
\hline pTB7037 & $\begin{array}{l}\mathrm{Ap}^{\mathrm{r}} ;\left(P_{-} p q q A B^{\prime}-l a c Z\right) 2.2 \mathrm{~kb} \text { SalI-BamHI fragment from pTB3070 with } \\
\text { promoter region of } p q q A B C D E \text { cloned into SalI-BamHI sites of pQF50 }\end{array}$ & This study \\
\hline pTB7040 & $\begin{array}{l}\mathrm{Tc}^{\mathrm{r}} \mathrm{Km}^{\mathrm{r}} ; 4.07 \mathrm{~kb} \text { PCR product of gene PA1976 with } \mathrm{Km}^{\mathrm{r}} \text { cassette cloned into } \\
\text { HindIII site of pEX18Tc }\end{array}$ & This study \\
\hline pTB7060 & $\begin{array}{l}\mathrm{Ap}^{\mathrm{r}} ; 1,67 \mathrm{~kb} \text { PCR product containing gene agmR cloned into the } \\
\text { Pst } \mathrm{I}-\mathrm{BamHI} \text { sites of pUCP20T }\end{array}$ & Gliese et al. (2004) \\
\hline рTB7070 & $\begin{array}{l}\mathrm{Ap}^{\mathrm{r}} \mathrm{Gm}^{\mathrm{r}} ; 1.04 \mathrm{~kb} \mathrm{Gm}^{\mathrm{r}} \text { cassette from pAC } \mathrm{Gm} \text { cloned into EcoRI site } \\
\text { of pUC18 }\end{array}$ & This study \\
\hline pTB7074 & $\begin{array}{l}\mathrm{Ap}^{\mathrm{r}} ;\left(P_{-} \text {exaDE } E^{\prime} \text {-lacZ) } 1.16 \mathrm{~kb} \text { promoter region of exaDE cloned into }\right. \\
\text { BglII-XbaI sites of pQF50 }\end{array}$ & Gliese et al. (2004) \\
\hline pTB7076 & $\begin{array}{l}\mathrm{Ap}^{\mathrm{r}} ; 1.18 \mathrm{~kb} \text { PCR product of gene PA3604 cloned into XbaI-HindIII } \\
\text { sites of pUC18 }\end{array}$ & This study \\
\hline pTB7077 & $\begin{array}{l}\mathrm{Ap}^{\mathrm{r}} \mathrm{Km}^{\mathrm{r}} ; 1.0 \mathrm{~kb} \text { SmaI-SmaI fragment of } \mathrm{Km}^{\mathrm{r}} \text { cassette cloned into ApaI-PstI } \\
\text { sites of pTB7076 }\end{array}$ & This study \\
\hline pТB7078 & $\begin{array}{l}\mathrm{Ap}^{\mathrm{r}} \mathrm{Km}^{\mathrm{r}} ; 1.94 \mathrm{~kb} \text { XbaI-HindIII fragment from pTB7077 cloned into } \\
\text { XbaI-HindIII sites of pEX18Ap }\end{array}$ & This study \\
\hline pTB7082 & $\begin{array}{l}\mathrm{Ap}^{\mathrm{r}} ;\left(P \_\mathrm{PA} 1991^{\prime}-\text { lacZ) } 0.53 \mathrm{~kb} \text { PCR product containing the promoter }\right. \\
\text { region of PA1991 cloned into the XbaI-HindIII sites of pQF50 (pPA1991) }\end{array}$ & This study \\
\hline
\end{tabular}


Table 2. cont.

\begin{tabular}{|c|c|c|}
\hline Strain or plasmid & Relevant genotype or phenotype & Source or reference \\
\hline pTB7083 & $\begin{array}{l}\mathrm{Ap}^{\mathrm{r}} ;\left(P \_\mathrm{PA} 1992^{\prime} \text {-lacZ) } 0.62 \mathrm{~kb} \text { PCR product containing the promoter region }\right. \\
\text { of PA1992 cloned into the XbaI-HindIII sites of pQF50 (pPA1992) }\end{array}$ & This study \\
\hline pTB7100 & $\mathrm{Ap}^{\mathrm{r}} ; 1.98 \mathrm{~kb}$ PCR product of gene PA1992 cloned into EcoRI-SphI sites of pUC18 & This study \\
\hline pTB7103 & $\begin{array}{l}\mathrm{Ap}^{\mathrm{r}} \mathrm{Gm}^{\mathrm{r}} ; 1.02 \mathrm{~kb} \text { BamHI fragment of } \mathrm{Gm}^{\mathrm{r}} \text { cassette cloned into BamHI site of } \\
\text { pTB7100 }\end{array}$ & This study \\
\hline pTB7104 & $\mathrm{Ap}^{\mathrm{r}} \mathrm{Gm}^{\mathrm{r}} ; 2.23 \mathrm{~kb} E c o \mathrm{RI}-X b a \mathrm{I}$ fragment from pTB7103 cloned into pEX18Ap & This study \\
\hline pTB7106 & $\begin{array}{l}\mathrm{Ap}^{\mathrm{r}} ; 1.18 \mathrm{~kb} \text { XbaI-HindIII fragment from pTB7076 cloned into XbaI-HindIII } \\
\text { sites of pUCP20T }\end{array}$ & This study \\
\hline
\end{tabular}

regulatory element in ethanol metabolism of $P$. aeruginosa ATCC 17933. It controls transcription of a regulon that comprises the operons exaBC and pqq and the twocomponent regulatory system exaDE. With the identification of genes PA1976, PA1992 and PA3604 as further two-component regulatory systems, we find apparently four levels of regulation. Here we introduce for all proteins involved in regulating the operons exa and pqq the name ethanol metabolism regulatory factors, indicating different levels, a, b, etc. for a hierarchical organization of twocomponent systems. The type of factor is indicated by $\mathrm{S}$ for sensor kinase and $\mathrm{R}$ for response regulator.

The exaDE two-component regulatory system controls transcription of the exaA operon and will be renamed. It represents the first level of regulation (Schobert \& Görisch, 2001), and is called eraSR. The response regulator AgmR represents the second level of regulation (Gliese et al., 2004), and is renamed ErbR. The two FlhS-like sensor kinases encoded by PA1976 and PA1992 are required for ErbR (AgmR) expression and can partially compensate for each other. These sensor kinases are named ErcS (PA1992) and ErcS' (PA1976). The FlhR-like response regulator encoded by gene PA3604 is named ErdR (fourth level of regulation). It is required for expression of ErcS and ErbR. The exa genes encoding components involved in ethanol oxidation and the different regulatory genes era to erd controlling the exa and pqq operons are listed in Table 1.

\section{Identification of genes possibly involved in regulating ethanol utilization}

Genes encoding components of the ethanol oxidation pathway (exa) and its regulation are clustered in the genome of $P$. aeruginosa. Fig. 1 shows the arrangement of the exaA, exaBC, eraSR (exaDE) and pqq operons as found in $P$. aeruginosa ATCC 17933 by sequencing a fragment of about $13 \mathrm{~kb}$ from cosmid pTB3001. An identical arrangement of these genes has been reported in P. aeruginosa PAO1 (Stover et al., 2000; Pseudomonas Genome Database; Winsor et al., 2009). Therefore, we use the gene numbers of $P$. aeruginosa $\mathrm{PAO} 1$ to identify genes in the present paper. Gene ercS' (PA1976), upstream of the exa gene cluster, and gene ercS (PA1992), downstream of the pqq genes, were found to encode two-component sensor kinases with significant amino acid sequence similarity in their Cterminal parts to FlhS in Paracoccus denitrificans. The twocomponent regulatory system FlhSR controls methanol, formaldehyde and methylamine oxidation in Paracoccus denitrificans (Harms et al., 2001). Gene erdR (PA3604) of $P$. aeruginosa encodes a putative response regulator and was identified by its $60 \%$ similarity to FlhR of Paracoccus denitrificans. In addition, the product of gene erdR also shows a $61 \%$ similarity in amino acid sequence with response regulator ErbR (AgmR), which controls transcription of the exa and pqq operons in $P$. aeruginosa (Gliese et al., 2004).

\section{Generation of regulatory mutants}

Mutants of $P$. aeruginosa ATCC 17933 were generated by inactivating the response regulator gene $\operatorname{erdR}$ and the two sensor kinase genes ercS' and ercS. The flhS-like gene ercS' was interrupted by a $\mathrm{Km}^{\mathrm{r}}$ cassette, resulting in mutant NG2; the second flhs-like gene ercS was inactivated by a combination of $\mathrm{Gm}^{\mathrm{r}}$ cassette insertion and deletion of a 640 bp fragment, resulting in mutant SH1. By interrupting gene ercS in mutant NG2, double mutant $\mathrm{SH} 2$ was generated, with both $f l h S$-like genes inactivated. The $f l h R$-like gene $\operatorname{erdR}$ was inactivated by a combination of $\mathrm{Km}^{\mathrm{r}}$ cassette insertion and deletion of a $262 \mathrm{bp}$ fragment, resulting in mutant MD1. A double mutant with both genes inactivated, the flhS-like $\operatorname{ercS}$ and the flhR-like erdR, was generated from mutant SH1 
by $\mathrm{Km}^{\mathrm{r}}$ cassette insertion and deletion of a $262 \mathrm{bp}$ fragment in gene $e r d R$, resulting in mutant MD2. The correct insertion of resistance cassettes and construction of mutants was verified by PCR product analysis (data not shown). The different mutants with their genotypes are listed in Table 2.

\section{Growth of regulatory mutants}

Growth behaviour of the mutants was determined on various substrates (Table 3). Mutant NG2 grew on all substrates tested like the wild-type. Inactivation of the FlhSlike sensor kinase $\mathrm{ErcS}^{\prime}$ apparently did not influence growth of the organism. However, inactivation of the FlhS-like sensor kinase ErcS, generating mutant $\mathrm{SH} 1$, caused a significant extension of the lag phase on ethanol, while the generation time was unaltered with respect to the wild-type. On glucose and succinate, mutant $\mathrm{SH} 1$ showed an increase in generation time. When gene $\operatorname{ercS}^{\prime}$ was inactivated in the background of mutant $\mathrm{SH} 1$, generating double mutant $\mathrm{SH} 2$ with both flhS-like genes, ercS' and ercS, inactivated, no growth at all occurred on ethanol for up to $50 \mathrm{~h}$ (Table 3). Both sensor kinases are therefore involved in regulation of ethanol utilization. Growth of mutant SH2 on glucose was retarded, while no effect was found on succinate or acetate.

Mutant MD1, with the flhR-like gene erdR inactivated, did not grow on ethanol for up to $80 \mathrm{~h}$. Therefore the intact response regulator ErdR is essential for ethanol utilization. Mutant MD1 did grow on glucose or succinate like the wild-type, but unlike mutant $\mathrm{SH} 2$, no growth was observed on acetate (Table 3). Double mutant MD2, in which the flhS-like gene ercS and the $f l h R$-like gene $\operatorname{erdR}$ were both inactivated, behaved like Mutant MD1 on ethanol, glucose and succinate (data not shown). Upon transformation in trans by plasmids carrying an intact copy of the inactivated chromosomal gene, all mutants showed wild-type behaviour again (data not shown).

\section{Transcription of the ethanol oxidation system in regulatory mutants}

Transcription of the operons exaA, eraSR (exaDE), exaBC and $p q q$ was studied using reporter gene constructs, with the respective promoter regions in vectors pEDY305 and pQF50. Transcription of the four operons of the ethanol oxidation system was reduced in all generated putative regulatory mutants. In mutant NG2, which did not show any difference in growth behaviour when compared with the wild-type, transcription of all four operons was reduced to $60-80 \%$ of that of the wild-type. In mutant SH1, transcription was reduced even further to $25-45 \%$ (Fig. 2). In double mutant $\mathrm{SH}$, with both flhS-like sensor kinase genes inactivated, and in mutant MD1, where an flhR-like gene was inactivated, transcription was reduced to a value below $2 \%$ with respect to the wild-type (data not shown). The results demonstrate that all three flh-like gene products are required for expression of the exa, eraSR (exaDE) and pqq operons in $P$. aeruginosa.

We previously reported (Gliese et al., 2004) that in mutant NG3, where gene erbR $(a g m R)$ is inactivated, the exaA, eraSR (exaDE), exaBC and pqq operons are not transcribed. This situation is identical to that found here with mutants SH2 and MD1. It appears that the FlhS-like sensor kinases ErcS $^{\prime}$ and ErcS as well as the FlhR-like response regulator ErdR are required for ErbR (AgmR) expression.

\section{Transcription of regulatory factors in the different regulatory mutants}

Reporter gene constructs with the promoter regions of $e r b R$ (agmR; pTB7108) and erdR (pTB7107) cloned into vector pQF50 allowed the determination of their transcription in the different mutants.

Table 3. Growth of $P$. aeruginosa mutants on various carbon sources

Results represent mean values of at least three independent experiments. SK, two-component regulatory system sensor kinase; RR, response regulator. Gen, generation time; Lag, lag phase; wt, wild-type value; $>$, generation time or lag phase greater than 1.5 times the wild-type value; $>>$, extreme lag phase of $20 \mathrm{~h}$; NG, no growth for at least $50 \mathrm{~h}$.

\begin{tabular}{|c|c|c|c|c|c|}
\hline \multirow{2}{*}{$\begin{array}{l}\text { P. aeruginosa ATCC } 17933 \\
\text { strain }\end{array}$} & \multirow[t]{2}{*}{ Gene inactivated } & \multicolumn{4}{|c|}{ Carbon source } \\
\hline & & Ethanol & Glucose & Succinate & Acetate \\
\hline $\begin{array}{l}\text { Mutant NG2 } \\
\left(\text { PA1976:: Km }{ }^{\mathrm{r}}\right)\end{array}$ & SK & $\begin{array}{c}\text { Gen/Lag } \\
\text { wt/wt }\end{array}$ & $\begin{array}{c}\text { Gen/Lag } \\
\text { wt/wt }\end{array}$ & $\begin{array}{c}\text { Gen/Lag } \\
\text { wt/wt }\end{array}$ & $\begin{array}{c}\text { Gen/Lag } \\
\text { wt/wt }\end{array}$ \\
\hline $\begin{array}{l}\text { Mutant SH1 } \\
\quad\left(\text { PA1992:: } \mathrm{Gm}^{\mathrm{r}}\right)\end{array}$ & SK & $w t />>$ & $>/$ wt & $>/$ wt & $w t />$ \\
\hline $\begin{array}{l}\text { Mutant SH2 } \\
\quad(\text { PA1976:: Km } \\
\text { PA1992:: }\end{array}$ & SK SK & NG & $>1>$ & wt/wt & wt/wt \\
\hline $\begin{array}{l}\text { Mutant MD1 } \\
\left(\text { PA3604:: Km }{ }^{\mathrm{r}}\right)\end{array}$ & $\mathrm{RR}$ & NG & $w t / w t$ & $\mathrm{wt} / \mathrm{wt}$ & $\mathrm{NG}^{*}$ \\
\hline
\end{tabular}

${ }^{\star}$ U. Kretzschmar, personal communication. 

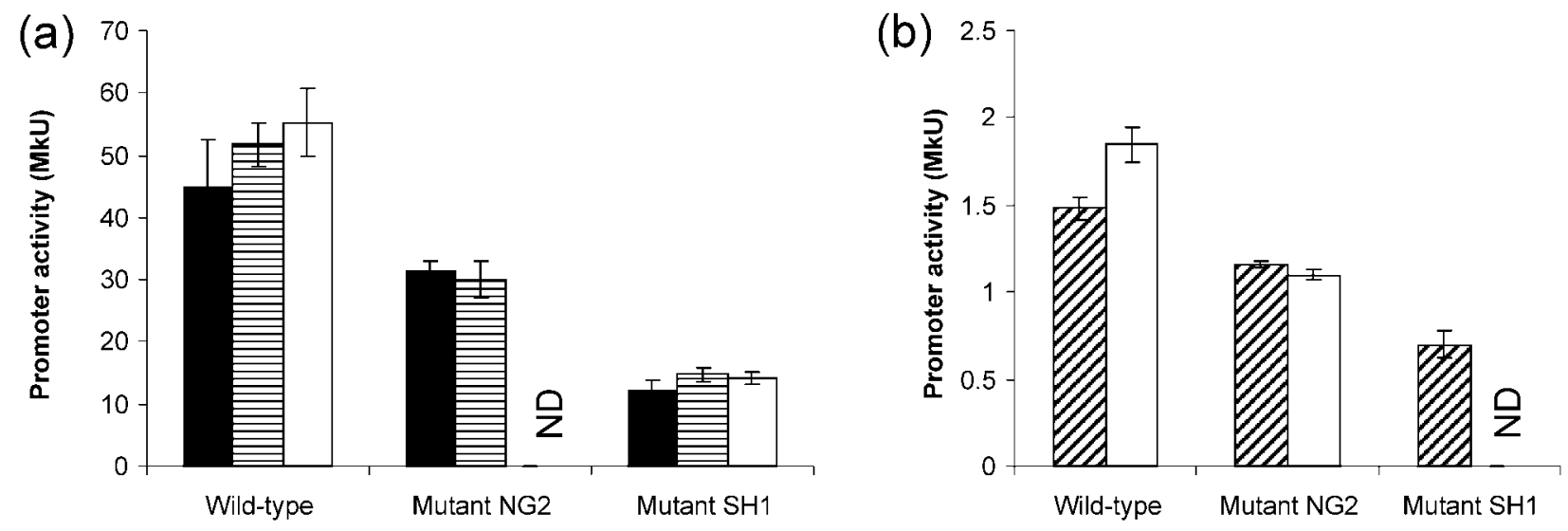

Fig. 2. Promoter activities of the exaA, eraSR (exaDE), exaBC and pqqABCDE operons in wild-type and mutant strains of $P$. aeruginosa after growth or induction on ethanol. (a) Promoter activities of exaA (pTB3138), exaBC (pTB3139) and pqqABCDE (pTB7023) using reporter constructs of pEDY305. Black bars, exa $A$; horizontally hatched bars, exaBC; white bars, pqqABCDE. (b) Promoter activities of eraSR (exaDE, pTB7074) and pqqABCDE (pTB7037) using reporter constructs of pQF50. Hatched bars, eraSR (exaDE); white bars, pqqABCDE. The promoter activities of exaA, eraSR (exaDE), exaBC and pqqABCDE in mutants SH2, MD1 and NG3 were less than $2 \%$ of the activities in the wild-type (not shown). Results represent mean values of at least three independent experiments. ND, Not determined.

Transcription of erbR $(\operatorname{agm} R)$ was reduced, albeit to different levels, in all the mutants with defective flhS- or flhR-like genes (Table 4). Therefore, sensor kinases ErcS' and ErcS and the response regulator ErdR all participate in controlling ErbR (AgmR) expression. The ErbR (AgmR) response regulator in turn controls transcription of the exa and pqq operons (Gliese et al., 2004).

Transcription of gene erdR, encoding an FlhR-like response regulator, was reduced only slightly in the respective defective mutants (Table 4). Apparently, its transcription does not depend on the FlhS-like sensor kinases ErcS' and ErcS or the response regulator ErbR (AgmR). ErdR appears to represent the highest level of regulatory components identified so far (Fig. 3).
The gene sequence of ercS, encoding an FlhS-like sensor kinase, overlaps with the upstream gene PA1991 by $17 \mathrm{bp}$. Presumably, the two genes form a transcriptional unit. To study the transcriptional regulation of ercS (PA1992), reporter gene constructs were generated with different putative promoter sequences. The putative promoter region of PA1991 together with part of gene PA1991 was amplified and cloned in the reporter gene vector pQF50, resulting in plasmid pTB7082. The construct pTB7082 records the transcriptional activity of a putative PA1991 promoter. By amplifying a sequence in front of ercS, which belongs to the coding sequence of PA1991, together with part of ercS, and cloning it into vector pQF50, plasmid pTB7083 was generated, which records the transcriptional activity of a putative promoter in front of ercS. Construct

Table 4. Promoter activities of genes erbR (agmR) and erdR in wild-type and mutant strains of $P$. aeruginosa after growth or induction on ethanol

I, after induction; $G$, after growth. Results represent mean \pm SD of at least three independent experiments.

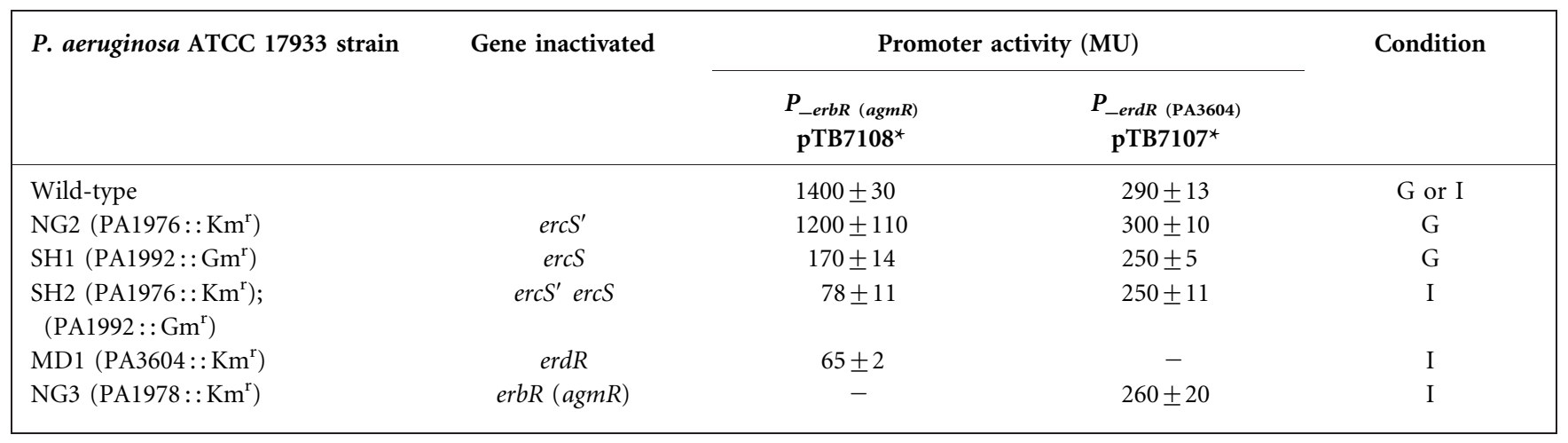

${ }^{*}$ pQF50 reporter constructs. 


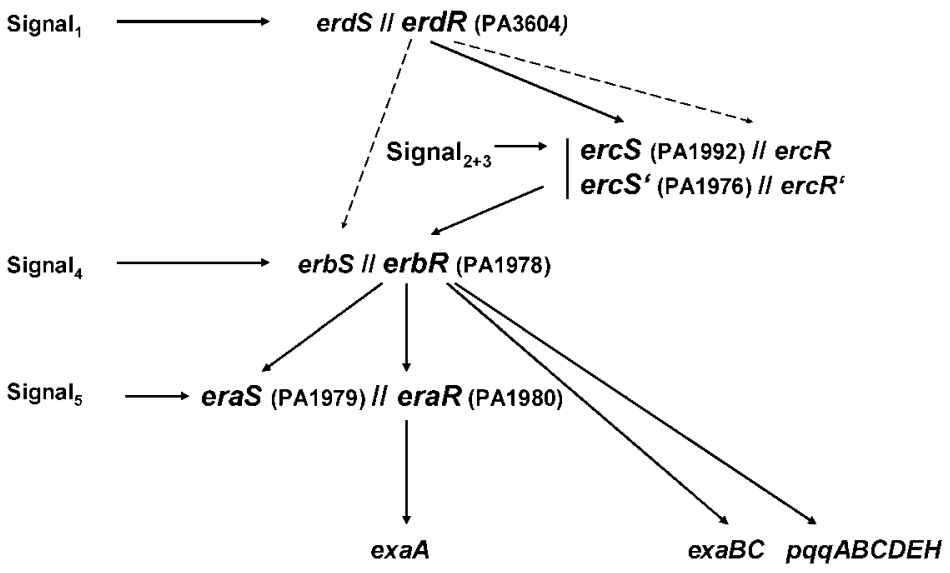

Fig. 3. Hypothetical regulatory scheme of a complex regulatory network controlling transcription of operons exa and $p q q$ of the quinoprotein ethanol oxidation system in $P$. aeruginosa ATCC 17933. Solid arrows indicate demonstrated positive control of transcription, broken arrows indicate assumed positive control of transcription. The identified genes encoding sensor kinases $S$ and response regulators $\mathrm{R}$ are shown in larger type than the corresponding two-component system genes not yet identified. //, Response regulator-sensor kinase pairing.

pTB7084 was generated by amplifying the sequence encompassing the putative promoter region of PA1991, the whole of gene PA1991, and part of gene ercS. This reporter records transcription of gene ercS as a function of the promoter in front of gene PA1991. The three constructs were transferred into $P$. aeruginosa wild-type and mutant MD1. After growth or induction on ethanol the activities of the reporter genes were determined (Table 5). The highest activity in the wild-type was found with pTB7082, where the putative PA1991 promoter is used and the reporter gene resides in PA1991. With pTB7083, the lowest activity was found, indicating that in front of $\operatorname{ercS}$ there is no strong promoter or no promoter at all. This conclusion is supported by the higher activity found with pTB7084, about $23 \%$ of the activity found with pTB7082. The two genes PA1991 and ercS (PA1992) form a transcriptional unit with a promoter in front of PA1991. The activity of ercS, however, seems to be downregulated with respect to that of PA1991.

To test whether transcription of the operon PA1991/ercS (PA1992) is impaired in mutant MD1, the activities of pTB7082 and pTB7084 were determined in the background of this mutant. As shown in Table 5, the activities of both reporter constructs were reduced significantly in mutant MD1. The promoter activity of gene PA1991 was only about $20 \%$ of that found in the wild-type, while the transcriptional activity of the sensor kinase encoded by ercS (PA1992) was even lower at about $12 \%$ of that found in the wild-type. Therefore, ErdR is required for expression of ErcS.

\section{Transcription of genes erbR (agmR), ercS and erdR on different substrates}

Transcription of gene ercS, encoding an FhlS-like sensor kinase, and genes $\operatorname{erbR}(\operatorname{agmR})$ and $\operatorname{erdR}$, encoding FlhRlike response regulators, was studied in wild-type $P$. aeruginosa grown on different substrates. The promoter activities of gene $\operatorname{erbR}(\operatorname{agmR})$ varied with the carbon source supplied for growth. With ethanol, the highest promoter activity of 1260 Miller units (MU) ( $\pm 7 \%$ ) was found, while on glucose and succinate, only 5-10\% of this value was detected. On butanol, $40 \%$, and on glycerol, $60 \%$ of the activity on ethanol was found. Therefore, transcription of gene erbR $(a g m R)$ is induced on ethanol, which then leads to induction of the exa and $p q q$ operons.

The promoter activities of the $\operatorname{ercS}$ gene studied with pTB7084 also varied with the carbon source. With ethanol, the highest activity of $250 \mathrm{MU}$ was found, but on glucose, only $14 \%$, and on succinate, only $22 \%$ of this value was detected. Thus, transcription of gene $\operatorname{ercS}$ was also induced on ethanol.

Transcription of gene erdR did not change when $P$. aeruginosa was grown on different carbon sources. On ethanol, butanol, glycerol, glucose and succinate, promoter activities of $360 \pm 30 \mathrm{MU}$ were found. Apparently, gene erdR is not induced by ethanol but is transcribed constitutively. The fact that transcription of $\operatorname{erdR}$ is not reduced in any of the regulatory mutants described so far, together with the observation that it is not induced by ethanol, suggests again that it forms the highest level of a hierarchical organization of two-component regulatory systems (Fig. 3).

\section{Constitutive expression of the FlhS-like sensor kinase ErcS does not restore transcription of operons exa and pqq in mutant MD1}

The FlhR-like response regulator ErdR is required for transcription of the FlhS-like sensor kinase encoded by ercS (Table 5). As can be seen in Fig. 2, mutant NG2, with a defect in sensor kinase ErcS' but an intact sensor kinase ErcS, showed appreciable expression of the operons exa and pqq. Expression vector pTB7101 carries gene ercS under the control of the lac promoter, which is recognized in $P$. aeruginosa and leads to constitutive expression of ErcS. Vector pTB7101 was transferred to mutant MD1 and expression of the exa and $p q q$ operons was determined using promoter-probe vectors pTB3138, pTB3139 and pTB7023. Constitutive expression of gene ercS, however, did not restore expression of the exa and pqq operons (data 
Table 5. Transcription of ercS in P. aeruginosa wild-type and mutant MD1 after growth or induction on ethanol

I, after induction; G, after growth. Results represent mean \pm SD of at least three independent experiments.

\begin{tabular}{|lccc|}
\hline P. aeruginosa ATCC $\mathbf{1 7 9 3 3}$ strain & Promoter-probe vector & Promoter activity (MU) & Condition \\
\hline Wild-type & pTB7082 & $1082 \pm 190$ & G or I \\
Wild-type & pTB7083 & $78 \pm 26$ & $\mathrm{G}$ \\
Wild-type & pTB7084 & $251 \pm 25$ & $\mathrm{G}$ \\
MD1 $\operatorname{erdR}\left(\mathrm{PA} 3604:: \mathrm{Km}^{\mathrm{r}}\right)$ & pTB7082 & $240 \pm 35$ & $\mathrm{I}$ \\
MD1 $\operatorname{erdR}\left(\mathrm{PA} 3604:: \mathrm{Km}^{\mathrm{r}}\right)$ & pTB7084 & $32 \pm 3.5$ & $\mathrm{I}$ \\
\hline
\end{tabular}

*pQF50 reporter constructs with the following putative promoter regions: pTB7082, P_PA1991'-lacZ; pTB7083, P_PA1992'-lacZ; pTB7084, P_PA1991/1992'-lacZ.

not shown). This result suggests that ErdR controls transcription of sensor kinase ErcS and a so far unknown corresponding response regulator ErcR. Constitutive expression of ErcS is not sufficient to start the signal cascade, because in mutant MD1 the corresponding response regulator $\mathrm{ErcR}$ will still be missing.

However, reduction of ercS transcription in mutant MD1 could also be explained by assuming that ErcS and ErdR constitute a single two-component regulatory system that is controlled by autoregulation. Inactivation of the response regulator gene $\operatorname{erdR}$ would cause lower transcription of the system. However, a similarly reduced transcription of erdR was not observed in mutants $\mathrm{SH} 1$ and SH2 (Table 4), which may indicate that autoregulation operates only on gene ercS. Mutant $\mathrm{SH} 2$, in which sensor kinase genes $\operatorname{ercS}$ and $\operatorname{ercS} S^{\prime}$ are inactivated, does not grow on ethanol but grows on acetate, while mutant MD1, with response regulator gene $\operatorname{erdR}$ inactivated, does not grow on ethanol and also not on acetate (Table 3 ). The different properties of the two mutants may indicate that ErcS' and ErcS are not cognate to ErdR. However, mutants showing different phenotypes may also be found upon inactivation of a sensor kinase or its cognate response regulator of a single two-component system. If the response regulator under consideration shows activation of activity in both its phosphorylated and its unphosphorylated state, the response regulator mutant will show a larger number of defects compared with the mutant with the inactivated cognate sensor kinase. Such a situation is observed with response regulator mutant MD1, which is unable to grow on ethanol or acetate, while sensor kinase mutant $\mathrm{SH} 2$ still grows on acetate. The observed behaviour might suggest that the response regulator ErdR supports growth on ethanol in its phosphorylated state but supports growth on acetate in its unphosphorylated form. Since upon growth on ethanol, acetate utilization is also needed, this seems to be an improbable scenario, indicating that sensor kinase ErcS and response regulator ErdR may not be cognate members of a single two-component regulatory system. The erd system then will be the higher-level one that controls transcription of the erc system (Fig. 3).

\section{Constitutive expression of ErbR (AgmR) restores expression of the ethanol oxidation system in mutant SH2 but not in mutant MD1}

Transcription of gene $\operatorname{erbR}(\operatorname{agmR})$ depends on the FlhSlike sensor kinases ErcS' and ErcS (Table 4). In mutant $\mathrm{SH} 2$, with both sensor kinases inactivated, gene erbR $(a g m R)$ was not transcribed and the activity of the exaA, exaBC and pqqAB promoters was less than $2 \%$ of that found in the wild-type (see legend to Fig. 2). Expression vector pTB7060 carries gene $\operatorname{erbR}(\operatorname{agmR})$ under the control of the lac promoter, which causes constitutive expression of ErbR (AgmR) in P. aeruginosa. Mutant SH2 was transformed by vector pTB7060, and constitutive expression of the response regulator ErbR (AgmR) partially restored the promoter activity of the exa and $p q q$ operons. Compared with the wild-type, the activity found for exaA was $41 \%$, that for exaBC $22 \%$, and that for pqqAB $69 \%$. The results confirm that transcription of the ethanol oxidation system is controlled by ErbR (AgmR).

The data suggest either that an active sensor kinase cognate to ErbR is expressed in mutant $\mathrm{SH} 2$ or that unphosphorylated ErbR (AgmR) has low transcriptional activity. Vector pTB7060 leads to constitutive expression of ErbR (AgmR), and even though the level of expression is not known, the concentration of ErbR (AgmR) may be sufficient to allow transcription of the exa and $p q q$ operons.

However, when vector pTB7060 was transferred to mutant MD1, no transcription of the exa and pqq operons was observed (data not shown). This result is not in agreement with the assumption of unphosphorylated ErbR (AgmR) having low transcriptional activity, since the expression level of ErbR with pTB7060 is expected to be the same in both mutants, MD1 and $\mathrm{SH} 2$.

From the experimental results with mutant $\mathrm{SH} 2$, in which by constitutive expression of ErbR (AgmR), transcription of exaA, exaBC and $p q q A B$ was found, it must be concluded that a sensor kinase corresponding to ErbR (AgmR) is present in the mutant. This sensor kinase activating ErbR (AgmR) cannot be ErcS' or ErcS, because both are inactivated in mutant $\mathrm{SH}$ 2. Therefore, sensor kinases ErcS' or ErcS and response regulator ErbR do not 
form a cognate pair, but rather are members of two different regulatory systems. The ercSR system is the higher-level one, which controls transcription of response regulator ErbR (AgmR) (Fig. 3). Transcription of the so far unknown sensor kinase ErbS cognate to ErbR (AgmR), however, seems not to be controlled by the ercSR system, because it is present in mutant $\mathrm{SH} 2$.

The gene encoding response regulator ErbR (AgmR) is located on the genome next to the two-component system EraSR (ExaDE); however, with the opposite orientation (Fig. 1). It could be argued that sensor kinase EraS (ExaD) might be responsible for phosphorylating ErbR (AgmR) also. As described in Schobert \& Görisch (2001), an inactive sensor kinase EraS (ExaD) in mutant MS13 or an inactive response regulator EraR (ExaE) in mutant MS12 both prevent transcription of gene exaA encoding QEDH, but not transcription of gene exaB encoding cytochrome $c_{550}$. Inactivation (Gliese et al., 2004) of response regulator ErbR (AgmR) in mutant NG3 prevents transcription of three different operons: eraSR (exaDE), exaBC and pqq. In the case of EraS (ExaD) being able to phosphorylate the response regulator ErbR (AgmR) in addition to EraR (ExaE), the differences observed with mutant MS13, defective in EraS (ExaD), and mutant NG3, defective in ErbR (AgmR), must be caused by the response regulator ErbR, whether phosphorylated or unphosphorylated, supporting the transcription of different genes. Such a scenario with respect to ErbR does not seem reasonable, because all functions impaired in mutant NG3 are needed for ethanol metabolism and are expected to be controlled by the phosphorylated form of ErbR. The differences observed with mutants MS13 and NG3 therefore indicate that EraS and ErbR are probably not cognate members of a two-component regulatory system.

In mutant $\mathrm{MD1}$, the response regulator ErdR is inactivated, and constitutive expression of ErbR (AgmR) by vector pTB7060 does not lead to transcription of the exa and pqq operons. It appears that ErdR is required for expression of the so far unknown sensor kinase ErbS cognate to ErbR (AgmR) (Fig. 3).

\section{Hypothetical complex network with five two- component regulatory systems organized hierarchically to control aerobic ethanol oxidation in $P$. aeruginosa}

Previously, based on studies with a limited number of regulatory mutants, it was concluded that at least seven genes are involved in regulating ethanol metabolism in $P$. aeruginosa (Görisch, 2003). The response regulator ErbR (AgmR) controls the transcription of operons exaBC, pqqABCDE and eraSR (exaDE), the last two-component system controlling the transcription of operon exaA (Gliese et al., 2004). The observation that transcription of the operons exaA, eraSR (exaDE), exaBC and pqqABCDE, and the response regulator gene $\operatorname{erbR}(\operatorname{agmR})$, is reduced or completely prevented in mutants NG2, SH1, SH2 and MD1 indicates that the genes inactivated in these mutants are required for transcription of the operons exa, pqq and era (Fig. 2, Table 4) by directing transcription of gene $\operatorname{erbR}$ $(a g m R)$ (Fig. 3). In the present study we identified two further sensor kinases and an additional response regulator involved in controlling transcription of the ethanol oxidation system. Of the three known sensor kinases, EraS (exaD), ErcS and ErcS', and the three known response regulators, EraR (ExaE), ErbR (AgmR) and ErdR, only EraSR are known to form a cognate pair (Schobert \& Görisch, 2001).

The present report demonstrates that several two-component regulatory systems are involved in regulating ethanol metabolism in P. aeruginosa. We provide sufficient evidence for a hierarchical organization of a number of sensor kinases and response regulators. An attempt to pair the known sensor kinases and the known response regulators to cognate members of two-component regulatory systems showed that a number of assumptions have to be made to achieve a satisfactory explanation for all the experimental data. Those assumptions include that the systems are autoregulated and that autoregulation is exerted only on the sensor kinase, while the response regulators involved must show different activating activities whether in the phosphorylated or unphosphorylated state. Improbable regulatory properties of the response regulators involved have to be assumed.

Such difficulties do not arise when making the simple assumption that there exist two additional sensor kinases cognate to ErdR and ErbR (AgmR) and two additional response regulators cognate to $\mathrm{ErcS}^{\prime}$ and $\mathrm{ErcS}$, as shown in Fig. 3. The systems are hierarchically organized, with four levels of sensor kinases and response regulators, and at least 10 genes organized in five different two-component systems are involved in regulating aerobic ethanol metabolism in P. aeruginosa (Fig. 3). This hypothetical regulatory scheme is the simplest one that explains all the experimental results without making further complicating assumptions. The model is, however, complex in the sense that five different two-component regulatory systems are involved. The hypothetical model depicted in Fig. 3 could be disproved by demonstrating direct phosphorylation of response regulators ErdR and ErbR (AgmR) by one of the known sensor kinases, or could be verified by identification of the so far unknown sensor kinase genes erdS and erbS and the unknown response regulator genes $\operatorname{erc} R^{\prime}$ and $\operatorname{ercR}$.

According to our hypothetical model, ErdR is a global response regulator which directs transcription of a regulon comprising the operons PA1991/ercS, ercS', the unknown erbS, and the genes encoding the unknown response regulators ErcR and ErcR' (Fig. 3). This global response regulator ErdR appears to be constitutively expressed, as was reported for response regulator FlhR, controlling metabolism of methanol and formaldehyde in Paracoccus denitrificans. The transcription of the response regulator gene erbR is controlled by the erc system. 
Gene $\operatorname{eraR}($ exaE) encodes a response regulator of 225 aa, erbR $(\operatorname{agmR})$ encodes one of 221 aa, and the ErdR protein is a 217 aa polypeptide. All three response regulators are members of the LuxR family and contain a CheY-type receiver domain and a helix-turn-helix DNA-binding motif.

Gene eraS (exaD) encodes a sensor kinase of 272 aa, which shows within the transmitter domain in the C-terminal portion a $33 \%$ similarity to histidine-type sensor kinases (Schobert \& Görisch, 2001). The EraS (ExaD) protein contains an internal methionine residue. In annotating the $P$. aeruginosa $\mathrm{PAO}$ sequence, the internal ATG codon was regarded as the actual start codon of a shorter putative sensor kinase, resulting in a predicted protein of 216 aa (Pseudomonas Genome Database; Winsor et al., 2009). However, in both cases, within the N-terminal domain of the putative sensor kinases neither a signal peptide nor transmembrane helices can be found. It appears that EraS $(\mathrm{ExaD})$ is a soluble protein localized in the cytoplasm. Gene ercS encodes a hybrid sensor kinase of 564 aa and gene ercS' one of 881 aa. Both ErcS and ErcS' show in their C-terminal portions $56 \%$ similarity to the sensor kinase FlhS of Paracoccus denitrificans. The FlhSR system in Paracoccus directs methanol and formaldehyde oxidation (Harms et al., 2001). Both sensor kinases, ErcS and ErcS', again do not contain in their $\mathrm{N}$-terminal domain a signal peptide or transmembrane helices. They are soluble proteins localized in the cytoplasm.

It is of interest to note that all three sensor kinases identified so far as involved in the regulation of aerobic ethanol metabolism in $P$. aeruginosa appear to be soluble cytoplasmic proteins. This implies that signals 2, 3 and 5 in Fig. 3 must be metabolites in the cytoplasm. This argument is in accord with the observation that several mutants with defects in genes encoding components of intermediary metabolism show impaired regulation of the ethanol oxidation system. Such is the case in mutants with inactivated genes proB (PA4565), encoding glutamate kinase, and gene $g l c B$ (PA0482), encoding malate synthase (unpublished data), and in a mutant with a defect in the aceA gene, encoding isocitrate lyase (Kretzschmar et al., 2008). So far, however, the data do not allow any metabolite to be pinpointed which might serve as an internal signal for one of the sensor kinases.

\section{ACKNOWLEDGEMENTS}

For access to $P$. aeruginosa PAO1 sequence information we used the Pseudomonas Genome Database (Winsor et al., 2009). This work was supported in part by grant Go 15-2 from the Deutsche Forschungsgemeinschaft, Bonn.

\section{REFERENCES}

Altschul, S. F., Madden, T. L., Schaffer, A. A., Zhang, J., Zhang, Z., Miller, W. \& Lipman, D. J. (1997). Gapped BLAST and PSI-BLAST: a new generation of protein database search programs. Nucleic Acids Res 25, 3389-3402.

Ausubel, F. A., Brent, R., Kingston, R. E., Moore, D. D., Seidman, J. G., Smith, J. A. \& Struhl, K. (editors) (2002). Current Protocols in Molecular Biology. New York: Wiley.

Boyer, H. W. \& Roulland-Dussoix, D. (1969). A complementation analysis of the restriction and modification of DNA in Escherichia coli. J Mol Biol 41, 459-472.

Cetin, E. T., Töreci, K. I. \& Ang, Ö. (1965). Encapsulated Pseudomonas aeruginosa (Pseudomonas mucosus) strains. J Bacteriol 89, 14321433.

Farinha, M. A. \& Kropinski, A. M. (1990). Construction of broad-hostrange plasmid vectors for easy visible selection and analysis of promoters. J Bacteriol 172, 3496-3499.

Figurski, D. H. \& Helinski, D. R. (1979). Replication of an origincontaining derivative of plasmid RK2 dependent on a plasmid function provided in trans. Proc Natl Acad Sci U S A 76, 16481652.

Ghosh, M., Anthony, C., Harlos, K., Goodwin, M. G. \& Blake, C. (1995). The refined structure of the quinoprotein methanol dehydrogenase from Methylobacterium extorquens. Structure 3, 177187.

Gliese, N., Khodaverdi, V., Schobert, M. \& Görisch, H. (2004). AgmR controls transcription of a regulon with several operons essential for ethanol oxidation in Pseudomonas aeruginosa ATCC 17933. Microbiology 150, 1851-1857.

Görisch, H. (2003). The ethanol oxidation system and its regulation in Pseudomonas aeruginosa. Biochim Biophys Acta 1647, 98-102.

Hanahan, D. (1983). Studies on transformation of Escherichia coli with plasmids. J Mol Biol 166, 557-580.

Harms, N., Reijnders, W. N. M., Koning, S. \& Van Spanning, R. J. M. (2001). Two-component system that regulates methanol and formaldehyde oxidation in Paracoccus denitrificans. J Bacteriol 183, 664-670.

Hoang, T. T., Karkhoff-Schweizer, R. R., Kutchma, A. J. \& Schweizer, H. P. (1998). A broad-host-range Flp-FRT recombination system for site-specific excision of chromosomally-located DNA sequences: application for isolation of unmarked Pseudomonas aeruginosa mutants. Gene 212, 77-86.

Keitel, T., Diehl, A., Knaute, T., Stezowski, J. J., Höhne, W. \& Görisch, H. (2000). X-ray structure of the quinoprotein ethanol dehydrogenase from Pseudomonas aeruginosa: basis of substrate specificity. J Mol Biol 297, 961-974.

Kretzschmar, U., Schobert, M. \& Görisch, H. (2001). The Pseudomonas aeruginosa acsA gene, encoding an acetyl-CoA synthetase, is essential for growth on ethanol. Microbiology 147, 2671-2677.

Kretzschmar, U., Khodaverdi, V., Jeoung, J. H. \& Görisch, H. (2008). Function and transcriptional regulation of the isocitrate lyase in Pseudomonas aeruginosa. Arch Microbiol 190, 151-158.

Lidstrom, M. E., Anthony, C., Biville, F., Gasser, F., Goodwin, P., Hanson, R. S. \& Harms, N. (1994). New unified nomenclature for genes involved in the oxidation of methanol in Gram-negative bacteria. FEMS Microbiol Lett 117, 103-106.

Matsushita, K., Shinagawa, E., Adachi, O. \& Ameyama, M. (1982). O-type cytochrome oxidase in the membrane of aerobically grown Pseudomonas aeruginosa. FEBS Lett 139, 255-258.

Mennenga, B., Kay, C. W. M. \& Görisch, H. (2009). Quinoprotein ethanol dehydrogenase from Pseudomonas aeruginosa: the unusual disulfide ring formed by adjacent cysteine residues is essential for efficient electron transfer to cytochrome $c_{550}$. Arch Microbiol 191, 361-367. 
Miller, J. M. (1992). A Short Course in Bacterial Genetics, a Laboratory Manual and Handbook for Escherichia coli and Related Bacteria. Cold Spring Harbor, NY: Cold Spring Harbor Laboratory.

Mutzel, A. \& Görisch, H. (1992). Quinoprotein ethanol dehydrogenase: preparation of the apo form and reconstitution with pyrrolloquinoline quinone and $\mathrm{Ca}^{2+}$ and $\mathrm{Sr}^{2+}$ ions. Agric Biol Chem 55, 1721-1726.

Reichmann, P. \& Görisch, H. (1993). Cytochrome $c_{550}$ from Pseudomonas aeruginosa. Biochem J 289, 173-178.

Rupp, M. \& Görisch, H. (1988). Purification, crystallization and characterization of quinoprotein ethanol dehydrogenase from Pseudomonas aeruginosa. Biol Chem Hoppe Seyler 369, 431-439.

Sambrook, J., Fritsch, E. F. \& Maniatis, T. (1989). Molecular Cloning: a Laboratory Manual, 2nd edn. Cold Spring Harbor, NY: Cold Spring Harbor Laboratory.

Schobert, M. (1999). Molekulargenetische Untersuchungen zum Ethanol-oxidierenden System in Pseudomonas aeruginosa. PhD thesis, Technische Universität Berlin, Germany.

Schobert, M. \& Görisch, H. (1999). Cytochrome $c_{550}$ is an essential component of the quinoprotein ethanol oxidation system in Pseudomonas aeruginosa: cloning and sequencing of the genes encoding cytochrome $c_{550}$ and an adjacent acetaldehyde dehydrogenase. Microbiology 145, 471-481.

Schobert, M. \& Görisch, H. (2001). A soluble two-component regulatory system controls expression of quinoprotein ethanol dehydrogenase $(\mathrm{QEDH})$ but not expression of cytochrome $c_{550}$ of the ethanol-oxidation system in Pseudomonas aeruginosa. Microbiology 147, 363-372.

Schwartz, E., Gerischer, U. \& Friedrich, B. (1998). Transcriptional regulation of Alcaligenes eutrophus hydrogenase genes. J Bacteriol 180, 3197-3204.

Schweizer, H. P. (1991). The agmR gene, an environmentally responsive gene, complements defective $g l p R$, which encodes the putative activator for glycerol metabolism in Pseudomonas aeruginosa. J Bacteriol 173, 6798-6806.
Schweizer, H. P. (1992). Allelic exchange in Pseudomonas aeruginosa using novel ColE1-type vectors and a family of cassettes containing a portable oriT and the counter selectable Bacillus subtilis sacB marker. Mol Microbiol 6, 1195-1204.

Schweizer, H. D. (1993). Small broad-host-range gentamycin resistance gene cassette for site-specific insertion and deletion mutagenesis. Biotechniques 15, 831-834.

Schweizer, H. P. \& Po, C. (1996). Regulation of glycerol metabolism in Pseudomonas aeruginosa: characterization of the $g l p R$ repressor gene. J Bacteriol 178, 5215-5221.

Schweizer, H. P., Klassen, T. R. \& Hoang, T. (1996). Improved methods for gene analysis in Pseudomonas. In Molecular Biology of Pseudomonads, pp. 229-237. Edited by T. Nakazawa, K. Furukawa, D. Haas \& S. Silver. Washington, DC: American Society for Microbiology.

Smith, A. W. \& Iglewski, B. H. (1989). Transformation of Pseudomonas aeruginosa by electroporation. Nucleic Acids Res 17, 10509.

Stover, C. K., Pham, X. Q., Erwin, A. L., Mizoguchi, S. D., Warrener, P., Hickey, M. J., Brinkman, F. S., Hufnagel, W. O., Kowalik, D. J. \& other authors (2000). Complete genome sequence of Pseudomonas aeruginosa PAO1, an opportunistic pathogen. Nature 406, 959-964.

Winsor, G. L., Van Rossum, T., Lo, R., Khaira, B., Whiteside, M. D., Hancock, R. E. \& Brinkman, F. S. (2009). Pseudomonas Genome Database: facilitating user-friendly, comprehensive comparisons of microbial genomes. Nucleic Acids Res 37, D483-D488.

Xia, Z., Dai, W. W., Zhang, Y., White, S. A., Boyd, G. D. \& Mathews, F. S. (1996). Determination of the gene sequence and the three-dimensional structure at $2.4 \AA$ resolution of methanol dehydrogenase from Methylophilus W3A1. J Mol Biol 259, 480-501.

Yanisch-Perron, C., Vieira, J. \& Messing, J. (1985). Improved M13 phage cloning vectors and host strains: nucleotide sequence of the M13mp18 and pUC19 vectors. Gene 33, 103-119.

Edited by: J. W. B. Moir 